\title{
0 conceito de unidade mínima de análise como eixo articulador do método marxiano e da psicologia concreta
}

Larissa Figueiredo Salmen Seixlack Bulhões

Márcio Magalhães da Silva

\section{RESUMO}

O presente trabalho elege o estudo do conceito de unidade mínima de análise no intuito de demonstrar os meios pelos quais os pressupostos metodológicos marxianos se realizam na investigação do psiquismo humano por Vigotski, que buscava lançar os fundamentos de uma psicologia concreta. A seleção desse conceito justifica-se pelo fato de este sintetizar o movimento dialético de ascensão do abstrato ao concreto multideterminado, o qual rege a revelação das leis gerais que submetem o desenvolvimento categorial dos fenômenos e desvenda as dissimulações da aparência fenomênica. Demonstrou-se que, da mesma forma que Marx anuncia a mercadoria como unidade mínima de análise da sociedade capitalista, Vigotski adota o signo como categoria fundamental que contém o psiquismo humano em sua totalidade, como síntese de determinações singulares e universais, individuais e sociais, biológicas e culturais, históricas e sociais, de significados e sentidos. Conclui-se que, em consonância com os fundamentos do materialismo histórico-dialético, a psicologia concreta deve buscar na unidade mínima de análise a superação das dicotomias lógico-formais e a especificidade do psiquismo humano, que tem na ação consciente o potencial para construir, sobre as cinzas das inversões burguesas, o devir de uma sociedade sem classes que tenha a humanidade como centro do processo produtivo.

Palavras-chaves: método marxiano; unidade de análise; psicologia concreta; Vigotski.

\section{ABSTRACT}

The concept of minimum unit of analysis as an articulating axis of the marxian method and concrete psychology

The present work chooses the study of the concept of a minimum unit of analysis in order to demonstrate the means by which the marxian methodological assumptions are realized in the investigation of human psyche by Vigotski, who sought to lay the foundations of a concrete psychology. The selection of this concept is justified by the fact that it synthesizes the dialectical movement of ascension from the abstract to the multi-determined concrete, which governs the revelation of the general laws that subject the categorical development of the phenomena and unveils the disguises of the phenomenal appearance. It was shown that, in the same way that Marx announces the commodity as the minimum unit of analysis of capitalist society, Vigotski adopts the sign as a fundamental category that contains the human psyche in its entirety, as a synthesis of singular and universal,, individual and social, biological and cultural, historical and social determinations of meanings and senses. We conclude that, in consonance with the foundations of historical-dialectic materialism, concrete psychology must seek in the minimum unit of analysis to overcome the logical-formal dichotomies and the specificity of the human psyche, which has in conscious action the pontential to build on the ashes of bourgeois inversions, the becoming of a classless society that has humanity as the center of the productive process.

Keywords: marxian method; analysis unit; concrete psychology; Vygotsky.

\section{Sobre os autores}

L. F. S. S. B.

http://orcid.org/0000-00028388-0036

Universidade Federal de Lavras

- Lavras, MG

larissa.bulhoes@ufla.br

M. M. S.

http://orcid.org/0000-0003-

1498-7670

Universidade Federal de Lavras

- Lavras, MG

marcio.dasilva@ufla.br

\section{Direitos Autorais}

Este é um artigo de acesso aberto e pode ser reproduzido livremente, distribuído, transmitido ou modificado, por qualquer pessoa desde que usado sem fins comerciais. 0 trabalho é disponibilizado sob a licença Creative Commons CC-BY-NC.

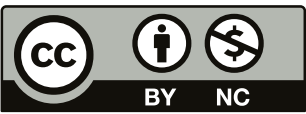




\section{INTRODUÇÃO}

"A psicologia precisa de seu O capital", afirma Vigotski (1927/2004, p. 393) no texto "O significado histórico da crise da psicologia". Para ele, n'O capital, Marx (1885/2014, $1867 / 2017 a, 1894 / 2017 b)$ apresentava a superação metodológica da descrição atomística e dicotômica dos fenômenos, movimento que se fazia necessário para a construção de uma psicologia científica, cujos fundamentos apreendessem a totalidade histórica implicada na formação da consciência. Portanto, o eixo metodológico de análise categorial implicado no materialismo histórico-dialético sustentou as prerrogativas delineadoras da psicologia vigotskiana. Tais pressupostos preconizaram a representação do movimento no qual se realizam as tensões dialéticas edificadoras da natureza social do psiquismo. Nesse contexto, inaugurou-se uma visão científica a qual transcendeu os preformismos, as biologizações e os psicologismos recorrentes nas dicotomias lógico-formais da psicologia tradicional ao anunciar as contradições essenciais da subjetividade humana como balizadoras de sua concretude multideterminada. Com tais correlações em vista, entendemos ser de grande importância explicitar os princípios da arquitetônica categorial marxiana de crítica à sociedade burguesa, os quais sustentaram epistemologicamente a construção de uma psicologia marxista em sua essência. Para tanto, o presente trabalho elege como eixo balizador o estudo do conceito de unidade mínima de análise, com o intuito de demonstrar os meios pelos quais os pressupostos metodológicos marxianos nele contidos se realizam no estudo do psiquismo pela psicologia histórico-cultural. A primazia desse conceito justifica-se pelo fato de que nele está sintetizado o movimento dialético de ascensão do abstrato ao concreto multideterminado, o qual rege a revelação das leis gerais que submetem o desenvolvimento categorial dos fenômenos e desvenda as inversões da superfície imediata, na qual qualquer produção rigorosamente científica fica inviabilizada.

\section{A UNIDADE MÍNIMA DE ANÁLISE NO MÉTODO MARXIANO}

0 método marxiano busca superar a lógica formal positivista, a qual surge no contexto de ascensão da burguesia ao poder (Netto, 2006). Tal conjuntura redundou na necessidade histórica de serem delineadas prerrogativas supostamente científicas que ocultassem as contradições essenciais do sistema capitalista e justificassem as desigualdades e explorações que edificavam a nova ordem social. A arbitrariedade desses pressupostos originários denuncia o caráter enviesado do que é denominado de ciência na sociedade burguesa, dado que a neutralidade que ela reivindica oculta determinações e interesses de classe, delineando o imperativo de se lançar mão de um novo método investigativo para a compreensão da realidade em sua essência (Marx, 201 1, 1867/2017a, $1894 / 2017 b)$. Nesse contexto o método marxiano emerge com a função histórica de, sobretudo, revelar e superar os fundamentos da lógica formal burguesa, os quais encobrem e preservam o funcionamento da sociedade de classes.

Portanto a escrita d'O Capital sintetiza os estudos de Marx, os quais visavam transcender a compreensão do mundo burguês pelo viés da economia política clássica (Marx, 1867/2017a). O pensador alemão denunciou os limites das teorias ancoradas na lógica formal, as quais reduziam-se a descrever a aparência imediata das categorias econômicas que compunham o sistema capitalista, redundando em conclusões não apenas equivocadas, mas, sobretudo, invertidas, sobre o funcionamento da ordem econômica e social vigente. A esta tendência estática e unilateral, Marx opôs o movimento da contradição, demonstrando que, para além de sua superfície harmônica, a sociedade burguesa se edifica sobre o frágil equilíbrio de nexos categoriais internos os quais tendem a se opor e a superar o próprio propósito acumulador do capital (Marx, 2011, 1885/2014, 1867/2017a, 1894/2017b; ver também Grespan, 2012; Rosdolsky, 2001).

Destarte, a trajetória traçada pelo pensador alemão ao longo dos três livros que compõem $O$ Capital sintetiza a objetivação precisa dos princípios norteadores do materialismo histórico-dialético. À vista disso, a clareza dos pressupostos que edificaram essa obra se configura na chave para o entendimento do método marxiano e, por conseguinte, para a apreensão da vulnerabilidade e transitoriedade dos antagonismos intrínsecos que, por ora, sustentam a sociedade burguesa.

É válido destacar que, de acordo com Marx (1985), toda a arquitetônica da análise materialista histórico-dialética das categorias econômicas burguesas teria sido um esforço desnecessário "se a forma de manifestação e a essência das coisas coincidissem imediatamente" (Marx, 1985, p. 271). Ou seja, na manifestação imediata dos fenômenos burgueses, a autonomização dos momentos que constituem o capital implica na perda aparente das conexões categoriais internas, de modo a encobrir as leis gerais que regem e que, ao mesmo tempo, negam seus pressupostos. Dados os objetivos do artigo em tela, nos dedicaremos a compreender as inversões categoriais inerentes à superfície burguesa, de modo a explicitar o papel fundamental da unidade mínima de análise na teoria marxiana.

É bastante difundida a célebre afırmação marxiana de que "O concreto é concreto por ser uma concentração (Zusammenfassung = concentração, síntese) de muitas determinações, logo, uma unidade do múltiplo" (Marx, 2010, p. 111). No texto em referência, Marx faz uma densa discussão sobre os pressupostos metodológicos adotados pela economia política, reivindicando, em contraposição ao movimento de análise 


\section{M." INTERACÃO EM LF PSICOLOGIA}

aplicado até então, a ascensão do abstrato ao concreto, dado que "as determinações abstratas conduzem à reprodução do concreto no plano (im Weg) do pensamento" (Marx, 2010, p. 111). Nesse contexto, alerta que, historicamente, o modo de apresentação dos clássicos da economia adotou a superfície imediata como ponto de partida da investigação (Marx, 2010). Tal fenômeno redundou em análises a-históricas e atomizadas, as quais pautaram-se em representações sincréticas do todo e reproduziram as inversões categoriais dissimuladoras do funcionamento essencial do modo de produção capitalista.

Objetivamente, essa dissimulação apresenta a sociedade capitalista como um "mundo encantado e distorcido", tal como Marx (1894/2017b, p. 889) o denomina no Livro III d'O Capital. Em consequência de tais mistificações, a sociedade burguesa, em sua expressão superficial, esconde propositalmente o exato oposto do que anuncia, de modo que: a contínua autovalorização do capital que impulsiona as relações de troca é diluída na suposta satisfação das necessidades dos trocadores; a contradição entre capital e trabalho se camufla na oposição entre os muitos capitais; a exploração do trabaIho, implicada na mais-valia, é mascarada ao ser transfigurada em lucro; a tendência interna da autonegação e autorrepulsão do capital se oculta na aparente necessidade externa de concorrência, a qual é naturalizada na esfera da pluralidade dos capitais (Marx, 2011, 1894/2017b; ver também Grespan, 2012; Rosdolsky, 2001). Tais inversões comprometem a apreensão do concreto como síntese multideterminada, o qual não pode ser alcançado no contato imediato com as representações burguesas dado que, na superfície fenomênica, as categorias econômicas são apresentadas como eternas e tem seus determinantes histórico-sociais diluídos.

0 autor adentra, portanto, a análise do processo de produção burguês a partir de uma esfera a qual sintetiza as expressões mais abstratas das categorias econômicas burguesas, denominada capital em geral (Marx, 2011; Rosdolsky, 2001). Para justificar esse ponto de partida analítico, Marx (1867/2017a, p. 78) afirma que, da mesma forma que o físico observa os processos naturais "em que eles aparecem mais nitidamente e menos obscurecidos por influências perturbadoras", buscando o "transcurso puro do processo" (Marx, 1867/2017a, p. 78), a faculdade de abstrair deve ser utilizada no intuito de compreender a expressão essencial das formas econômicas. O capital em geral consiste, nesse sentido, na apreensão do movimento categorial em suas determinações mais simples, de modo a revelar seu funcionamento por meio do isolamento das variáveis perturbadoras que autonomizam e invertem sua essência contraditória. Daí o anúncio da mercadoria como unidade mínima de análise, dado que esta, enquanto forma celular da economia burguesa, contém em si a expressão singular das tendências civilizatórias desse modo de produção (Marx, 2011, 1867/2017a). Essa prerroga- tiva inicial desnuda o capital como relação social, cuja plena compreensão só pode ser alcançada a partir de sua relação contraditória com a força de trabalho - contradição esta essencialmente expressa na existência dupla da mercadoria. Conforme nos aponta o autor:

Em primeiro lugar: o simples fato de que a mercadoria existe duplamente, uma vez como produto determinado que contém idealmente (contém de modo latente) seu valor de troca em sua forma de existência natural e, depois, como valor de troca manifesto (dinheiro) que removeu por sua vez todo nexo com a forma natural de existência do produto, essa dupla existência distinta tem de continuar até a diferença, a antítese e a contradição (Marx, 2011, p. 96, grifos do autor).

De fato, a construção lógica do método marxiano envolve a progressiva revelação do movimento essencial no qual as diferenças, antíteses e contradições categoriais internas se realizam a partir de sua exteriorização em relações sucessivamente mais complexas. Tais relações ocultam em si e, ao mesmo tempo, movem-se por meio das negações que sustentam e fragilizam o modo de produção do capital. Ou seja, as oposições intrínsecas às categorias econômicas burguesas não se resolvem, tampouco se superam; seu movimento alimenta-se da metamorfose das formas sociais, impondo-se e se diluindo à medida que as variáveis da superfície fenomênica se tornam mais concretas (Grespan, 2019; Marx, 2011).

Em coerência, portanto, com as determinações menos desenvolvidas que competem à abstração da esfera do capital em geral (Rosdolsky, 2001), a análise da arquitetônica categorial marxiana inicia-se nas prerrogativas da circulação mercantil simples, cuja expressão imediata aparenta ser "um verdadeiro Éden dos direitos inatos do homem" (Marx, $1867 / 2017$ a, p. 250), dado que se apresenta como mediadora de relações livres e igualitárias de troca de mercadorias pautadas nas necessidades humanas. Contudo, Marx demonstrará que em sua essência "sucedem processos inteiramente diferentes nos quais desaparece essa aparente igualdade e liberdade dos indivíduos" (Marx, 2011, p. 190). Tal demonstração implica no desenvolvimento das contradições internas da mercadoria na circulação mercantil simples, "desde a sua figura mais simples e discreta até a brilhante forma dinheiro" (Marx, 1867/2017a, p. 125), exigindo a inserção de variáveis progressivamente mais complexas para a apreensão das categorias nas quais as suas oposições se exteriorizam - valor de uso, valor de troca, mais valor, e assim por diante. Nessa metamorfose da expressão contraditória do valor, a força de trabalho aparece como a mercadoria cuja especificidade faz a conexão entre a circulação mercantil e a circulação do capital (Grespan, 2019). 


\section{H* INTERACÃO EM PSICOLOGIA}

É o movimento de contínua exteriorização dos antagonismos latentes na unidade mínima de análise, portanto, que irá revelar as leis gerais direcionadoras da produção e reprodução essencial do mundo burguês. Consequentemente, demonstra-se a interdependência categorial que carrega em si e, por conseguinte, redunda na insolúvel e semovente contradição entre capital e trabalho, a qual será objeto de dissimulação recorrente na superfície fenomênica. Tal movimento revela, por isso, que a busca do capital em camuflar sua total dependência da força de trabalho assalariada o leva a perder de vista sua própria medida, dado que oculta de si mesmo a verdadeira origem do valor, tornando-se suscetível às crises que escancaram sua natureza antagônica, histórica e, portanto, finita (Grespan, 2012; Marx, 2011, 1894/2017b; Rosdolsky, 2001).

Destarte, o conceito de unidade mínima de análise realiza a construção da arquitetônica categorial em seu mais alto nível de abstração e direciona o processo investigativo ao concreto como síntese multideterminada. Nesse processo, revela, gradativamente, que as determinações internas da lógica burguesa se realizam por meio das leis do valor, as quais demarcam a progressiva acumulação de capital como finalidade última do processo produtivo. Para além disso, denuncia que tal finalidade se edifica sobre frágeis antagonismos os quais contém em seu próprio movimento o potencial para superá-la, destruindo o simulacro que sustenta a afirmação do capital como totalidade frente ao trabalho e construindo, sobre as cinzas das inversões burguesas, uma sociedade que tenha o ser humano como centro do processo produtivo.

\section{A UNIDADE MÍNIMA DE ANÁLISE NA PSICOLOGIA CONCRETA}

Se para Marx (1932/2007) a filosofia (e a ciência) não deve se limitar a interpretar o mundo, pois o que importa é transformá-lo, é certo que ao expor a sua crítica da economia política n'O capital ele não pretendia apenas tornar conhecido o funcionamento da sociedade capitalista, mas apontar as vias de superação dessa sociedade, desvelando as suas contradições internas e possibilidades reais, concretas, de transformação, para que a construção de uma sociedade sem classes pudesse efetivamente ocorrer. Da mesma maneira, Vigotski $(2000,2001,2004,2018)$ busca na Psicologia compreender os processos psicológicos com a finalidade última de superar a deformação da humanidade produzida pela divisão da sociedade em classes e pelas relações de dominação que se estabeleceram entre elas ao longo da história, possibilitando a formação de uma nova humanidade, livre da exploração. Essa finalidade, que podemos traduzir como necessidade não apenas de conhecer mas de controlar os processos psicológicos, pela maneira como foi exposta na obra vigotskiana, aliada ao conhecimento do método marxiano, permite-nos avançar no entendimento da psicologia histórico-cultural como a psicologia geral que Vigotski (1927/2004) entendia ser necessária para avançarmos na formulação de uma psicologia concreta, isto é, uma psicologia capaz de apreender o indivíduo não como entidade abstrata, mas os indivíduos reais, objetivamente existentes, em sua concretude como seres singulares, e intervir na sua formação. Segundo Puzirei (Em Vigotski, 2000, p. 43):

Vigotski formula como uma das especificidades fundamentais de tal psicologia [geral] sua orientação para a psicotécnica em sentido amplo desta palavra, isto é para a técnica do trabalho prático com o psiquismo, sua transformação, seu domínio e desenvolvimento. 0 objetivo de tal psicologia não é Shakespeare em conceitos, como diz Dilthey, mas a psicotécnica, em uma palavra, isto é a teoria científica, a qual conduziria a subordinação e domínio do psiquismo, para o controle artificial da conduta.

A primeira tarefa na formulação de uma psicologia concreta consiste, portanto, em identificar o objeto exclusivo dessa ciência, tendo em vista que o indivíduo em sua concretude não pode ser reduzido a fatos psicológicos, portanto não pode ser objeto unicamente da Psicologia. Dessa maneira, faz-se necessário identificar o que seja um fato psicológico propriamente humano para, posteriormente, identificar a unidade de análise desse objeto, já que a Psicologia até hoje não foi capaz de produzir um consenso acerca dessas questões. Do ponto de vista do método marxiano, ao tomar o comportamento como objeto, por exemplo, e estudar o comportamento animal para explicar o comportamento humano, como faz a psicologia comportamental, a Psicologia viola um princípio da dialética materialista segundo o qual um objeto só pode ser devidamente apreendido se, ao estudá-lo, partirmos de sua forma mais complexa, mais desenvolvida, e não da mais simples, menos desenvolvida. Vigotski (1927/2004) questiona então se é correto considerar, por exemplo, os movimentos peristálticos (movimentos involuntários do esôfago e intestinos) como fatos psicológicos, na medida em que tomamos o comportamento como objeto da Psicologia e entendemos como comportamento tudo o que um organismo faz. Se isso estivesse correto, entendemos que a Psicologia seria desnecessária, já que esse mecanismo pode ser explicado no âmbito da fisiologia.

O objeto da Psicologia, portanto, deve ser algo que revele a singularidade psicológica de cada indivíduo na universalidade das relações humanas, que se distingue das relações entre as espécies animais por serem relações não naturais, isto é, históricas e sociais, relações de produção das condições de existência da humanidade em seu conjunto e de cada indivíduo como ser singular. Politzer (1928/1973), na sua crítica dos fundamentos da Psicologia, afirma que o objeto dessa 


\section{H*' INTERACÃO EM LTPSICOLOGIA}

ciência é a vida humana, não a mesma que estuda a Biologia, mas a vida humana como drama, ressaltando que com esse termo ele simplesmente designa o fato de a vida humana se distinguir das demais, abstraindo dessa palavra qualquer conotação romântica. E por que exatamente a vida humana se distingue das outras formas de vida? Segundo Politzer (1928/1973), porque os seres humanos não vivem simplesmente, mas atribuem sentido às suas vidas, transformando-as em narrativas (dramas) que são expressão do psiquismo individual. Além disso, como nos ensina Marx (1867/2017a), porque os seres humanos, sendo parte da natureza, não são dominados por ela, como os animais, mas submetem-na aos seus interesses, transformando-a, e dominam a si mesmos. Nesse processo de autodominação, dominam seus processos psicológicos, o que leva Vigotski a reconhecer como humanização do indivíduo a conquista do autodomínio da conduta. 0 objeto da Psicologia, portanto, é a vida ou o drama individual subordinado não à natureza, mas ao próprio indivíduo, entendido como síntese de determinações universais e singulares, biológicas, históricas e sociais. Vigotski (2000, p. 35, grifo do autor) incorpora o conceito de drama de Politzer à psicologia histórico-cultural ao afirmar que "O drama realmente está repleto de luta interna impossível nos sistemas orgânicos: a dinâmica da personalidade é o drama".

Se a Psicologia toma como objeto de estudo a vida ou o drama individual, resta saber como analisar psicologicamente a vida humana, decompondo-a sem descaracterizá-la. Trata-se, em outras palavras, de descobrirmos qual é a sua unidade mínima de análise. Esta, dentro da perspectiva marxiana, caracteriza-se como a forma molecular do psiquismo humano, a categoria mais simples que contém em si a essência do psiquismo humano, isto é, a atividade consciente. Isso porque, em consonância com o materialismo histórico-dialético, tomar o drama individual como ponto de partida da análise seria análogo a iniciar o estudo da economia burguesa pelos conceitos sincréticos de nação, população ou mesmo pelo trabalho: teríamos, como resultado, uma "representação (Vorstellung) caótica do todo" (Marx, 2010, p. 109). O próprio Politzer (1928/1973) compreende que o drama precisa ser decomposto ao afirmar que "os fatos psicológicos deverão ser os segmentos da vida do indivíduo particular" (Politzer, 1928/1973, p. 73). A abstração, portanto, conforme explicitamos anteriormente na explanação sobre o capital em geral, configura-se na principal ferramenta de análise do método marxiano, de modo que esta decomposição momentânea se faz fundamental para o alcance do concreto como síntese multideterminada.

Se a vida humana, em termos psicológicos, deve tender para o autocontrole da conduta, como pressupõe Vigotski $(2000,2001,2018)$, a sua unidade de análise deve condensar, como expressão do psiquismo propriamente humano, aquilo que viabiliza esse controle, a consciência. Portanto, na obra vigotskiana, os signos configuram-se como unidade mínima de análise do psiquismo por se constituírem como objetivações de capacidades humanas historicamente desenvolvidas, dentre as quais a própria capacidade de atuar conscientemente, que distingue o psiquismo humano. Dessa maneira, o signo consiste no estímulo artificial que controla a conduta individual materializando-se inicialmente nas relações interpessoais, e se caracteriza, assim, como instrumento de controle externo do psiquismo, e posteriormente se traslada e se torna instrumento de controle interno individual, distinguindo o psiquismo humano pela possibilidade de o indivíduo submeter as influências externas às internas, individuais, conscientemente. $O$ signo, como aponta Vigotski, submete externa ou internamente todos os processos psicológicos, determinando inclusive a prevalência de uns sobre outros a cada instante, bem como as relações que se estabelecem entre eles, na medida em que cada processo é parte de um sistema de processos interdependentes e intervinculados.

Outras unidades de análise, porém, aparecem na obra vigotskiana, como a vivência e a palavra ou o seu significado. A vivência, como Vigotski (2018) a define na sua quarta aula de pedologia, é a unidade personalidade-meio. Caracteriza-se, portanto, não como unidade de análise do psiquismo, mas da influência que o ambiente exerce sobre o indivíduo na análise do desenvolvimento infantil, tema da quarta aula. Dessa maneira, a vivência é uma unidade que estabelece como princípio metodológico a relativização do ambiente, tendo em vista o fato de que o ambiente não exerce uma influência capaz de desencadear em quaisquer indivíduos a mesma reação, pois, se assim o fosse, o ser humano seria escravo das contingências e não poderia jamais agir conscientemente, determinando internamente sua conduta, de tal maneira que, na vivência, personalidade e meio se determinam mutuamente. Cabe destacar, no entanto, que a relativização do ambiente na vivência é condicionada objetivamente pela relação metabólica que o indivíduo necessita estabelecer com a realidade, bem como pela própria objetividade material dos processos subjetivos, não devendo ser confundida com o solipsismo. A palavra, por sua vez, opera como signo, e, por esse motivo, pode ser tomada como unidade de análise do psiquismo, embora seja empregada inicialmente por Vigotski (2001) como unidade dos processos funcionais linguagem e pensamento. O significado, por outro lado, como conteúdo interno da palavra que não se externaliza diretamente, não pode ser tomado isoladamente como unidade de análise dos processos psicológicos simplesmente porque não é acessível se não se vincular a um significante, isto é, se não se exprimir por palavras escritas ou faladas.

Os signos, de maneira geral, possuem uma dimensão aparente, o significante, que ao mesmo tempo revela e oculta 


\section{M*' INTERACÃO EM LF PSICOLOGIA}

uma dimensão de significados e sentidos diversos, condensando em si as formas de controle da conduta historicamente criadas pela humanidade. Uma palavra, por exemplo, configura-se como signo porque é empregada no processo dialógico como instrumento de controle da conduta de um indivíduo por outro ao fazer emergir na relação interpessoal um conteúdo convencionado socialmente, estável e conhecido pelas pessoas envolvidas, o significado social da palavra. Ao mesmo tempo, essa mesma palavra pode fazer emergir conteúdos diferentes para cada indivíduo, sentidos pessoais elaborados e reelaborados nas vivências que, por definição, são particulares, e do fato de que o significado das palavras se constitui no processo de generalização, que implica a abstração das particularidades dos objetos que designam, eliminadas na sua função comunicativa, mas preservadas no seu conteúdo interno, na sua função intelectual. Politzer (1928/1973) emprega o termo sentido de forma semelhante, entendendo que o sentido é o conteúdo essencial do fato psicológico, na medida em que é o conteúdo propriamente individual. Segundo esse autor "o que interessa no acto psicológico não é a sua matéria e forma, mas o seu sentido; e este só pode ser esclarecido através dos dados fornecidos por uma narrativa do próprio sujeito" (Politzer, 1928/1973, p. 107).

A palavra, portanto, condensa na relação significado-sentido a unidade indivíduo-sociedade ou singular-universal, como o signo em geral. Conclui-se, assim, que somente o signo se configura como unidade de análise dos processos psicológicos, na medida em que contém em si e controla todos eles, sensações, percepção, atenção, memória, linguagem, pensamento, imaginação, emoções, motricidade, externa ou internamente. Dessa maneira, o estudo de qualquer processo isolado só pode ter como unidade de análise o signo, que preserva as relações e os vínculos interfuncionais do psiquismo, bem como as relações entre significado social e sentido pessoal, ou seja, entre sociedade e indivíduo na sua máxima concretude. Um gesto indicador, por exemplo, pelo significado social que possui e pelos sentidos que adquire nas vivências pode afetar um indivíduo fazendo-o estabelecer, voluntária ou involuntariamente, um novo foco de atenção e alterar o seu campo perceptual, captar novas sensações, registrar ou evocar conteúdos de memória diferentes, palavras, pensamentos, projetos, emoções, ações etc. Nesse sentido, ainda que se estude o efeito do gesto indicador sobre a atenção, não se pode ignorar que esse processo não ocorre isoladamente, pode ser dirigido espontânea ou voluntariamente ao ser percebido pelo indivíduo, inclui componentes afetivos, motores, e que o objetivo da Psicologia com um estudo desse tipo é possibilitar que o indivíduo seja capaz de controlar esse processo, ao invés de ser controlado por ele, como ocorre naturalmente. Da mesma maneira, o estudo das emoções não pode prescindir das relações destas com os movimentos corporais que as exprimem ou ocultam e com o pensamento, que distingue as emoções humanas das emoções que também expressam os animais, e assim por diante. Somente por essa via, como fica evidente, a Psicologia pode superar, inclusive, a dualidade corpo-mente estabelecida pelo pensamento cartesiano, já que os signos se constituem como objetivações de funções corporais e psíquicas indissociáveis.

Para finalizar, gostaríamos de fazer algumas considerações sobre a unidade de análise psicológica do processo educativo. Entendendo que a unidade de análise deve condensar a totalidade das relações que compõem o processo em estudo, e que a análise da dimensão psicológica da educação consiste na análise do processo de internalização dos conteúdos escolares que aparecem inicialmente nas relações intersubjetivas estabelecidas entre professor/a' e estudantes, a unidade de análise deve tomar o conhecimento escolar como signo, na sua unidade de conteúdo e forma e como parte das vivências do/a professor/a e das/os estudantes, porque o signo não é algo em si mesmo, eterno e imutável, mas é signo para pessoas diferentes que lhes atribuem significados e sentidos também diferentes. Tal fato se atesta quando um signo que sabidamente produz um certo efeito sobre o comportamento das pessoas em geral produz um efeito inesperado sobre o comportamento de outra específica. Assim, uma análise psicológica do processo educativo em sua concretude demanda conhecimento do conteúdo escolar em estudo, da metodologia de ensino empregada, e de quem são professor/a e

\footnotetext{
${ }^{1}$ Este trabalho adota linguagem inclusiva, explicitando os gêneros masculino e feminino (ex: professor/a) e utilizando, sempre que possível, termos neutros em gênero (ex: crianç, estudante, pessoa), conforme sugerido pelo campo dos estudos feministas (Furlani, 2011 ), mesmo entendendo que a transformação da língua sem a superação do capitalismo não transformará a realidade no sentido da superação da desigualdade de gênero. Em defesa da proposta de adoção da linguagem inclusiva entendemos que, se ela não é revolucionária, tampouco é contrarrevolucionária em si mesma, e, pelo estranhamento e eventualmente incômodo que causa, pode romper com automatismos que privilegiam o masculino no uso da palavra como meio de comunicação e instrumento do pensamento, ou seja, entendendo que, ao nos impormos o uso do feminino no discurso oferecemo-nos a oportunidade de pensar nas demandas específicas das mulheres, historicamente negligenciadas pelo fato de vivermos em uma sociedade machista, sustentada por relações de dominação patriarcais. Assim, se existe uma proposta de uso não espontaneísta, de transformação consciente da linguagem, que compreende a linguagem como produção humana, histórica e cultural, portanto sujeita a transformações, não existe, no nosso ponto de vista, justificativa para rejeitarmos essa proposta, se na perspectiva marxista partimos do pressuposto de que é justamente a possibilidade de transformação consciente da realidade, em qualquer dos seus aspectos, o que nos torna humanos. Por fim, se entendemos que o objetivo da educação é (trans)formar as consciências para produzir a superação do capitalismo, parte desse projeto consiste em denunciar as diversas formas de dominação e opressão que sustentam essa sociedade, dentre as quais a invisibilização histórica do gênero feminino, articulando essa discussão à dominação de classe, e não simplesmente ignorando-a ou menosprezando-a.
} 


\section{MLE INTERACÃO EM LTPSICOLOGIA}

estudantes em suas particularidades. Professoras/es e estudantes pertencem a uma classe social, mas essa classe não constitui a totalidade dos indivíduos, pois, para além da classe, existem outras determinações, de crenças, etnia/raça, gênero, orientação sexual, dentre outras, que atuam sobre cada um/a ou são percebidas mais imediatamente, e não podem ser ignoradas porque interferem na relação de cada pessoa consigo mesma e com o mundo. Além disso, professoras/es e estudantes nem sempre tem consciência de classe, e isso é fundamental para compreendermos as relações que se estabelecem na educação, tanto dos indivíduos entre si como dos indivíduos com o conhecimento. Assim, do ponto de vista da psicologia concreta, entendemos que não basta às/aos professoras/es conhecer o conteúdo que devem ensinar, a forma de ensinar, e as/os estudantes em sua concretude, mas é necessário também autoconhecimento, que abrange o conhecimento de si e sobre si, definidos por Leontiev (1978) como o conhecimento que um indivíduo tem de suas características de personalidade atreladas à sua situação social ou condição de classe. Portanto, em suma, devem constituir a unidade de análise psicológica do processo educativo (1) o signo, ou seja, o conteúdo escolar, em sua unidade de conteúdo e forma, (2) a forma como ele aparece na relação de ensino e aprendizagem, e os polos da relação intersubjetiva na qual ele aparece, isto é, (3) quem é o/a professor/a e (4) quem são as/os estudantes. Só assim é possível apreender o signo em movimento, em pelo menos dois momentos essenciais: no início do processo como instrumento interpsíquico, na relação entre professor/a e estudante, e no final do processo como instrumento intrapsíquico, quando é incorporado pela/o estudante.

\section{CONCLUSÃO}

A primazia da unidade mínima de análise como ponto de partida do movimento investigativo marxiano permite a transcendência das relações de troca no mundo burguês em direção à apreensão essencial do capital, submetendo suas categorias a um método que se qualifica como revolucionário por compreendê-las em sua totalidade multideterminada, delimitar sua reconstrução lógica e histórica e revelar as tendências internas de autonegação e superação do capital desde suas formas embrionárias. Tendo esses pressupostos em vista, vale ressaltar que a construção da ciência psicológica à luz das premissas metodológicas do materialismo histórico-dialético implicou no estudo do psiquismo humano direcionado pela arquitetônica categorial marxiana. Dessa forma, a psicologia concreta anunciou a interfuncionalidade do psiquismo encontrando no signo sua forma elementar e fundamental de expressão. Isso porque nele residem as contradições históricas essenciais que constituem o psiquismo, as quais resolvem-se exteriorizando-se nas demais categorias de análise da psique e, por conseguinte, constituindo o movimento de construção da subjetividade humana. De outro modo, o conceito de unidade mínima de análise permite superar atomismos e fragmentações em direção à compreensão de que a conquista da condição consciente do psiquismo humano depende das contínuas requalificações advindas dos antagonismos entre processos elementares e complexos, biológicos e culturais, materiais e ideais, consolidados e iminentes, e assim por diante.

Do exposto conclui-se que, quando Vigotski (1927/2004) se propõe a criar $O$ capital da Psicologia, não significa que ele pretenda encontrar em Marx a resposta para a pergunta: o que é o psiquismo humano? Diferentemente ele busca apreender, da obra marxiana, o movimento metodológico que possibilite responder a essa questão, como ele mesmo explicita, de tal modo que a ciência psicológica finalmente supere a fragmentação do seu campo em abordagens diversas e incompatíveis entre si, expressão de uma crise sobre a qual ele discorre em 1927 e perdura até hoje, passados mais de 90 anos! Diante disso, entendemos ser de fundamental importância a correta identificação da unidade mínima de análise do psiquismo humano tendo em vista que, como o presente artigo procurou demonstrar ao reconhecer o signo como essa unidade, nela está contido o psiquismo humano em sua totalidade, como síntese de determinações singulares e universais, individuais e sociais, biológicas e culturais, históricas e sociais, de significados e sentidos. Fundamentalmente, o signo contém aquilo que distingue o psiquismo humano do animal, a consciência, sem a qual seria impossível a ação humana transformadora da realidade, por conseguinte toda a história da humanidade, o próprio surgimento da sociedade capitalista e o devir de uma sociedade sem classes.

\section{CONTRIBUIÇÃO DE CADA AUTOR}

Certificamos que todos os autores participaram suficientemente do trabalho para tornar pública sua responsabilidade pelo conteúdo. A contribuição de cada autor pode ser atribuída como se segue:

L.F.S.S.B. e M.M.S. fizeram a redação inicial do artigo (rascunho) e são os responsáveis pela redação final (revisão e edição).

\section{DECLARAÇÃO DE CONFLITOS DE INTERESSE}

Os autores declaram que não há conflitos de interesse no manuscrito submetido. 


\section{W NTERAC̄̃OEM IT PSICOLOGIA}

\section{REFERÊNCIAS}

Furlani, J. (2011). Educação sexual na sala de aula: relações de gênero, orientação sexual e igualdade étnico-racial numa proposta de respeito às diferenças. Autêntica Editora.

Grespan, J. (2019). Marx e a crítica do modo de representação capitalista. Boitempo.

Grespan, J. (2012). O negativo do capital: o conceito de crise na crítica de Marx à economia política. Expressão Popular.

Leontiev, A. N. (1978). Actividad, conciencia y personalidad. Ediciones Ciencias del Hombre.

Marx, K. (1985). Manuscritos Economia y Filosofia (11a ed.). Editorial Alianza.

Marx, K. (2007). Ad Feuerbach. Em Marx, K.; Engels, F. A ideologia alemã. (R. Enderle, N. Schneider, L. C. Martorano, Trad., pp. 533-535). Boitempo. (Trabalho original publicado em 1932).

Marx, K. (2010). O método da economia política. Crítica Marxista, n.30, pp. 103-125.

Marx, K. (2011). Grundrisse: manuscritos econômicos de 18571858: esboços da crítica da economia política. Boitempo.

Marx, K. (2014). O capital: crítica da economia política: livro II: o processo de circulação do capital (R. Enderle, Trad.). Boitempo. (Trabalho original publicado em 1885).

Marx, K. (2017a). O capital: crítica da economia política: livro I: o processo de produção do capital (R. Enderle, Trad.). Boitempo. (Trabalho original publicado em 1867).
Marx, K. (2017b). O capital: crítica da economia política: livro III: o processo global da produção capitalista (R. Enderle, Trad.). Boitempo. (Trabalho original publicado em 1894).

Netto, J. P. (2006). O que é marxismo? Brasiliense.

Politzer, G. (1973). Crítica dos fundamentos da psicologia I. (Conceição Jardim e Eduardo Lúcio Nogueira, Trad.). Editorial Presença. (Trabalho original publicado em 1928)

Rosdolsky, R. (2001). Gênese e estrutura de O Capital de Karl Marx. EDUERJ: Contraponto.

Vigotski, L. S. (2000). Manuscrito de 1929. Educação \& Sociedade, 21(71), 21-44. https://doi.org/10.1590/S010173302000000200002 .

Vigotski, L. S. (2001). A construção do pensamento e da linguagem. (Paulo Bezerra, Trad.). Martins Fontes.

Vigotski, L. S. (2004). O significado histórico da crise da psicologia: uma investigação metodológica. In Vigotski, L. S. Teoria e método em psicologia. (Claudia Berliner, Trad., 3a ed., pp. 203-417). Martins Fontes. (Trabalho original publicado em 1927)

Vigotski, L. S. (2018). Sete aulas sobre os fundamentos da pedologia. E-papers.
Submetido em: $10 / 04 / 20$ $1^{\text {a }}$ decisão editorial: $27 / 04 / 20$ Aprovação: 29/04/20 